\title{
Stability of Convergence Theorems of the Noor Iteration Method for an Enumerable Class of Continuous Hemi Contractive Mapping in Banach Spaces
}

\author{
Akanksha Sharma ${ }^{1 *}$, Kalpana Saxena ${ }^{2}$ and Namrata Tripathi ${ }^{1}$ \\ ${ }^{1}$ Department of Mathematics, Technocrats Institute of Technology, Bhopal, Madhya Pradesh, India \\ ${ }^{2}$ Department of Mathematics, Govt. Motilal Vigyan Mahavidyalya, Bhopal, Madhya Pradesh, India
}

\begin{abstract}
The purpose of this is to study the Noor iteration process for the sequence $\{x\}$ converges to a common fix point for enumerable class of continuous hemi contractive mapping in Banach spaces.
\end{abstract}

Keywords: Stability; Noor iterations; Hemicontractive mapping; Convergence theorem; Continuous pseudocontractive mapping

2000 Mathematics Subject Classification: 47J25, 47H10, 54H25

\section{Introduction}

Let $\mathrm{E}$ be a real Banach space and let $\mathrm{J}$ denote the normalized duality mapping from $\mathrm{E}$ to $E^{\star}$ defined by

$$
J(x)=\left\{f \in E^{*}:\langle x, f\rangle=\|x\|\|f\|,\|x\|=\|f\| \text { for all } x \in E,\right.
$$

Where $E^{*}$ denotes the dual space of $\mathrm{E}$ and $\langle.,$.$\rangle denotes the$ generalization duality pair.

It is well known that if $E^{*}$ is strictly convex then J is single-valued. In the sequel, we shall denote the single-valued duality mapping by $\mathrm{j}$. Let $\mathrm{k}$ be a nonempty closed convex subset of Banach space $\mathrm{E}$ and $\mathrm{T}: \mathrm{K} \rightarrow K$ be a self-mapping of $\mathrm{K}$.

Definition 3.1: (i) A mapping $\mathrm{T}$ with domain $\mathrm{D}(\mathrm{T})$ and range $\mathrm{R}(\mathrm{T})$ in a Banach space is called pseudocontrative mapping, if for all $\mathrm{x}, \mathrm{y} \in \mathrm{D}(\mathrm{T})$, there exists $j(x-y) \in J(x-y)$ such that [1]

$$
\langle T x-T y, j(x-y)\rangle \leq\|x-y\|^{2}
$$

(ii) A mapping $\mathrm{T}$ with domain $\mathrm{D}(\mathrm{T})$ and range $\mathrm{R}(\mathrm{T})$ in $\mathrm{E}$ is called a hemicontractive mapping if $\mathrm{F}(\mathrm{T}) \neq \varnothing$ and for all $x \in D(T) x^{*} \in F(T)$ such that,

$$
\left\langle T x-x^{*}, j\left(x-x^{*}\right)\right\rangle \leq\left\|x-x^{*}\right\|^{2}
$$

(iii) A mapping $\mathrm{T}: \mathrm{K} \rightarrow K$ is called L-Lipschitizan there exists $\mathrm{L}>0$ such that

$$
\|T x-T y\| \leq L\|x-y\| \text { For all } \mathrm{x}, \mathrm{y} \in \mathrm{K}
$$

Definition 3.2: If $\left\{\propto_{n}\right\}_{\mathrm{n}=0}^{\infty}$ and $\left\{\beta_{n}\right\}_{\mathrm{n}=0}^{\infty}$ are sequences of real numbers in $[0,1]$ [2]. For arbitrary $x_{0} \in \mathrm{E}$, Let $\left\{x_{n}\right\}_{\mathrm{n}=0}^{\infty}$ be a Noor iteration defined by,

$$
\begin{aligned}
& x_{n+1=}\left(1-\propto_{n}\right) x_{n}+\propto_{n} T q_{n} \\
& q_{n}=\left(1-\beta_{n}\right) x_{n}+\beta_{n} T r_{n} \\
& r_{n}=\left(1-\beta_{n}\right) x_{n}+\beta_{n} T r_{n}
\end{aligned}
$$

Lemma 3.3: Let $\mathrm{E}$ be a real uniformly convex Banach space [3], $\mathrm{K}$ is nonempty closed convex subset of $\mathrm{E}$ and $\mathrm{T}$ a continuous pseudocontractive mapping of $\mathrm{K}$, then $I-T$ is demiclosed at zero, that is, for all sequences $\left\{x_{n}\right\} \subset \mathrm{K}$ with $x_{n} \rightarrow p$ and $x_{n}-T x_{n} \rightarrow 0$ it follows that $\mathrm{p}=\mathrm{Tp}$
Lemma 3.4: Let $\delta$ be a number satisfying $0 \leq \delta<1$ and $\left\{\epsilon_{n}\right\}$ a positive sequence satisfying $\lim _{n \rightarrow \infty} \in_{n}=0$ [4,5]. Then, for any positive sequence $\left\{u_{n}\right\}$ satisfying: $u_{n+1} \leq \delta u_{n}+\epsilon_{n}$, It follows that $\lim _{n \rightarrow \infty} u_{n}=0$.

\section{Results}

Theorem 4.1: Let $\left\{T_{n}\right\}_{\mathrm{n}=1}^{\infty}$ be defined as above and $F:=\bigcap_{(i=1)}^{\infty} F\left(T_{(n)} \neq \phi\right)$ and let $(\mathrm{E},\|\|$.$) be a Banach space, \mathrm{T}: \mathrm{E} \rightarrow \mathrm{E}$ a self-map of $\mathrm{E}$ with a fixed point $\mathrm{p}$, satisfying the contractive condition

$\left\langle T x-x^{*}, j\left(x-x^{*}\right)\right\rangle \leq\left\|x-x^{*}\right\|^{2}$ For $x_{0} \in E$.

Let $\left\{x_{n}\right\}_{\mathrm{n}=1}^{\infty}$ is converge to $\mathrm{p}$ and defined by the iteration (3.2) where $\left\{\propto_{n}\right\}_{\mathrm{n}=1}^{\infty}$ is a real sequence in $(0,1)$ and define as $\epsilon_{n}=\left\|x_{n+1}-\left(1-\propto_{n}\right) x_{n}-\propto_{n} T q_{n}\right\|$ Then

$\lim _{n \rightarrow \infty}\left\|x_{n}-p\right\|$ exists for all $\mathrm{p} \in F$;

$\lim _{n \rightarrow \infty} \mathrm{d}\left(x_{n}, F\right)=\left\{\right.$ inf $\left.\left\|x_{n}-p\right\|: p \in F\right\} ;$

$\left\{x_{n}\right\}$ converges strongly to a common fixed point of $\left\{T_{n}\right\}_{\mathrm{n}=1}^{\infty}$ if and only if $\lim _{n \rightarrow \infty} \mathrm{d}\left(x_{n}, F\right)=0$

Proof: Let $p \in F$ and $n \geq 1$ by 3.1 we choose $j\left(x_{n}-p\right) \in J\left(x_{n}-p\right)$ such that

$$
\begin{aligned}
& \left\|x_{n+1}-p\right\|^{2}=\left\langle x_{n+1}-p, j\left(x_{n+1}-p\right)\right\rangle \\
& \left\|x_{n+1}-p\right\| \leq\left\|x_{n+1}-\left(1-\propto_{n}\right) x_{n}-\propto_{n} T q_{n}\right\|+\left\|\left(1-\propto_{n}\right) x_{n}+\propto_{n} T q_{n}-p\right\| \\
& =\epsilon_{n}+\left\|\left(1-\propto_{n}\right) x_{n}+\propto_{n} T q_{n}-\left(\left(1-\propto_{n}\right)+\propto_{n}\right) p\right\| \\
& =\epsilon_{n}+\left\|\left(1-\propto_{n}\right)\right\| x_{n}-p\left\|+\propto_{n}\left(T q_{n}-p\right)\right\|
\end{aligned}
$$

*Corresponding author: Akanksha Sharma, Department of Mathematics Technocrats Institute of Technology, Bhopal, Madhya Pradesh, India, Tel: 07552751679; E-mail: akanksha0027@gmail.com

Received June 25, 2015; Accepted July 27, 2015; Published July 30, 2015

Citation: Sharma A, Saxena K, Tripathi N (2015) Stability of Convergence Theorems of the Noor Iteration Method for an Enumerable Class of Continuous Hemi Contractive Mapping in Banach Spaces. J Appl Computat Math 4: 239. doi:10.4172/2168-9679.1000239

Copyright: ( 2015 Sharma A, et al. This is an open-access article distributed unde the terms of the Creative Commons Attribution License, which permits unrestricted use, distribution, and reproduction in any medium, provided the original author and source are credited. 


$$
\begin{aligned}
& \leq \epsilon_{n}+\left(1-\propto_{n}\right)\left\|x_{n}-p\right\|+\propto_{n}\left\|T q_{n}-p\right\| \\
& =\epsilon_{n}+\left(1-\propto_{n}\right)\left\|x_{n}-p\right\|+\propto_{n}\left\|p-T q_{n}\right\| \\
& \leq \epsilon_{n}+\left(1-\propto_{n}\right)\left\|x_{n}-p\right\|+\propto_{n} a\left\|p-q_{n}\right\| \\
& =\epsilon_{n}+\left(1-\propto_{n}\right)\left\|x_{n}-p\right\|+\propto_{n} a\left\|q_{n}-p\right\|
\end{aligned}
$$

For the estimate of in (1) we get

$$
\begin{aligned}
& \left\|q_{n}-p\right\|=\left\|\left(1-\beta_{n}\right) x_{n}+\beta_{n} T r_{n}-p\right\| \\
& =\left\|\left(1-\beta_{n}\right) x_{n}+\beta_{n} T r_{n}-\left(\left(1-\beta_{n}\right)+\beta_{n}\right) p\right\| \\
& =\left\|\left(1-\beta_{n}\right)\left(x_{n}-p\right)+\beta_{n}\left(T_{n}-p\right)\right\| \\
& \leq\left(1-\beta_{n}\right)\left\|x_{n}-p\right\|+\beta_{n}\left\|T r_{n}-p\right\| \\
& =\left(1-\beta_{n}\right)\left\|x_{n}-p\right\|+\beta_{n}\left\|p-T r_{n}\right\| \\
& \leq\left(1-\beta_{n}\right)\left\|x_{n}-p\right\|+\beta_{n} a\left\|p-r_{n}\right\| \\
& =\left(1-\beta_{n}\right)\left\|x_{n}-p\right\|+\beta_{n} a\left\|r_{n}-p\right\|
\end{aligned}
$$

Substituting (2) into (1) gives

$\left\|x_{n+1}-p\right\| \leq \epsilon_{n}+\left(1-(1-a) \propto_{n}-\propto_{n} \beta_{n} a\right)\left\|x_{n}-p\right\|+\propto_{n} \beta_{n} a^{2}\left\|r_{n}-p\right\|$

For $\left\|r_{n}-p\right\|$ in (3) we have,

$$
\begin{aligned}
& \left\|r_{n}-p\right\|=\left\|\left(1-\gamma_{n}\right) x_{n}+\gamma_{n} T x_{n}-p\right\| \\
& =\left\|\left(1-\gamma_{n}\right) x_{n}+\gamma_{n} T x_{n}\left(\left(1-\gamma_{n}\right)+\gamma_{n}\right)-p\right\| \\
& =\left\|\left(1-\gamma_{n}\right)\left(x_{n}-p\right)+\gamma_{n}\left(T x_{n}-p\right)\right\| \\
& \leq\left(1-\gamma_{n}\right)\left\|x_{n}-p\right\|+\gamma_{n}\left\|T x_{n}-p\right\| \\
& =\left(1-\gamma_{n}\right)\left\|x_{n}-p\right\|+\gamma_{n}\left\|p-T x_{n}\right\| \\
& \leq\left(1-\gamma_{n}\right)\left\|x_{n}-p\right\|+\gamma_{n} a\left\|p-x_{n}\right\| \\
& =\left(1-\gamma_{n}+\gamma_{n} a\right)\left\|x_{n}-p\right\|
\end{aligned}
$$

Substituting (4) into (3) and using lemma 3.3

$$
\begin{aligned}
& =\epsilon_{n}+\left(1-(1-a) \propto_{n}-\propto_{n} \beta_{n} a\right)\left\|x_{n}-p\right\|+\propto_{n} \beta_{n} a^{2}\left(1-\gamma_{n}+\gamma_{n} a\right)\left\|x_{n}-p\right\| \\
& =\epsilon_{n}\left(1-(1-a) \propto_{n}-(1-a) \propto_{n} \beta_{n} a-(1-a) \propto_{n} \beta_{n} \gamma_{n} a^{2}\right)\left\|x_{n}-p\right\| \\
& \leq\left(1-(1-a) \alpha-(1-a) \alpha \beta a-(1-a) \alpha \beta \gamma a^{2}\right)\left\|x_{n-1}-p\right\|+\epsilon_{n}
\end{aligned}
$$

Observe that

$$
0 \leq\left(1-(1-a) \alpha-(1-a) \alpha \beta a-(1-a) \alpha \beta \gamma a^{2}\right)<1
$$

Therefore, taking the limit as $n \rightarrow \infty$ of both sides of the inequality (5) and using lemma 1.6 we get

$$
\lim _{n \rightarrow \infty}\left\|x_{n}-p\right\|=0 \text {, That is } \lim _{n \rightarrow \infty} x_{n=} p
$$

By theorem $3.2\left\|x_{n}-p\right\| \leq\left\|x_{n-1}-p\right\|$
Taking infimum over all $p \in F$, we have,

$$
d\left(x_{n}, F\right)=\underset{p \in F}{i n f}\left\|x_{n}-p\right\| \leq_{p \in F}^{i n f}\left\|x_{n-1}-p\right\|=d\left(x_{n-1}, F\right),
$$

Thus $\lim _{n \rightarrow \infty} d\left(x_{n}, F\right)$ exist we finally prove (iii) suppose that $x_{n} \rightarrow p \in F$ from (ii) and

$d\left(x_{n}, F\right) \leq\left\|x_{n}-p\right\| \rightarrow 0$, We have $\lim _{n \rightarrow \infty} d\left(x_{n}, F\right)=0$ for $\mathrm{n}, \mathrm{m} \in \mathbb{N}$ and $p \in F$, it follows

From (1.3) that

$$
\left\|x_{n+m}-x_{n}\right\| \leq\left\|x_{n+m}-p\right\|+\left\|x_{n}-p\right\| \leq\left\|x_{n}-p\right\|
$$

Consequently,

$$
\left\|x_{n+m}-x_{n}\right\| \leq 2\left\|x_{n}-F\right\| \rightarrow 0
$$

Therefore $\left\{x_{n}\right\}$ is a Cauchy sequence. Suppose $\lim _{n \rightarrow \infty} x_{n}=u$ for some $u \in E$. Then

$$
d(u, F)=\lim _{n \rightarrow \infty} d\left(x_{n}, F\right)=0
$$

Since $\mathrm{F}$ is closed set, $u \in F$

So, Noor iteration process is $T$-stable.

\section{Conclusion}

Thus, the stability of Noor iteration considerable for finding fixed point for enumerable class of continuous hemi contractive mapping in Banach spaces.

\section{References}

1. Browder FE, Petryshyn WV (1967) Construction of fixed points of nonlinear mappings in Hilbert space. J Math Anal Appl 20: 197-228.

2. Noor MA (2000) New approximations schemes for general variational inequalities. J Math Anal Appl 251: 217-299.

3. Chen $R$, Song $Y$, Zhou H (2006) Convergence theorems for implicit iteration process for a finite family of continuous pseudocontractive mappings. J Math Anal Appl 314: 701-709.

4. Takahashi W (2000) Nonlinear Functional Analysis Fixed Point Theory and its Applications. Yokohama Publishers Inc.

5. Zhou H (2008) Convergence theorems of common fixed points for a finite family of Lipschitz pseudocontractions in Banach spaces. Nonlinear Anal 68: $2977-$ 2983. 